\title{
TO THE MOON
}

'What have you looked at, Moon, In your time,

Now long past your prime?'

' $\mathrm{O}, \mathrm{I}$ have looked at, often looked at

Sweet, sublime,

Sore things, shudderful, night and noon

In my time.'

'What have you mused on, Moon,

In your day,

So aloof, so far away?'

' $\mathrm{O}, \mathrm{I}$ have mused on, often mused on

Growth, decay,

Nations alive, dead, mad, aswoon,

In my day!'

'Have you much wondered, Moon,

On your rounds,

Self-wrapt, beyond Earth's bounds ?'

'Yea, I have wondered, often wondered

At the sounds

Reaching me of the human tune

On my rounds.'

'What do you think of it, Moon, As you go?

Is Life much, or no?'

' $\mathrm{O}, \mathrm{I}$ think of it, often think of it

As a show

God ought surely to shut up soon,

As I go.' 